\title{
Bone regeneration by the osteoconductivity of porous titanium implants manufactured by selective laser melting: A histological and micro computed tomography study in the rabbit
}

de Wild, Michael ; Schumacher, Ralf ; Mayer, Kyrill ; Schkommodau, Erik ; Thoma, Daniel ; Bredell, Marius ; Kruse Gujer, Astrid ; Grätz, Klaus W ; Weber, Franz E

\begin{abstract}
The treatment of large bone defects still poses a major challenge in orthopaedic and cranio-maxillofacial surgery. One possible solution could be the development of personalized porous titanium-based implants that are designed to meet all mechanical needs with a minimum amount of titanium and maximum osteopromotive properties so that it could be combined with growth factor-loaded hydrogels or cell constructs to realize advanced bone tissue engineering strategies. Such implants could prove useful for mandibular reconstruction, spinal fusion, the treatment of extended long bone defects, or to fill in gaps created on autograft harvesting. The aim of this study was to determine the mechanical properties and potential of bone formation of light weight implants generated by selective laser melting (SLM). We mainly focused on osteoconduction, as this is a key feature in bone healing and could serve as a back-up for osteoinduction and cell transplantation strategies. To that end, defined implants were produced by SLM, and their surfaces were left untreated, sandblasted, or sandblasted/acid etched. In vivo bone formation with the different implants was tested throughout calvarial defects in rabbits and compared with untreated defects. Analysis by micro computed tomography $(\mu \mathrm{CT})$ and histomorphometry revealed that all generatively produced porous Ti structures were well osseointegrated into the surrounding bone. The histomorphometric analysis revealed that bone formation was significantly increased in all implant-treated groups compared with untreated defects and significantly increased in sand blasted implants compared with untreated ones. Bone bridging was significantly increased in sand blasted acid-etched scaffolds. Therefore, scaffolds manufactured by SLM should be surface treated. Bone augmentation beyond the original bone margins was only seen in implant-treated defects, indicating an osteoconductive potential of the implants that could be utilized clinically for bone augmentation purposes. Therefore, designed porous, lightweight structures have potential for bone regeneration and augmentation purposes, especially when complex and patient-specific geometries are essential.
\end{abstract}

DOI: https://doi.org/10.1089/ten.TEA.2012.0753

Posted at the Zurich Open Repository and Archive, University of Zurich

ZORA URL: https://doi.org/10.5167/uzh-82044

Journal Article

Published Version

Originally published at:

de Wild, Michael; Schumacher, Ralf; Mayer, Kyrill; Schkommodau, Erik; Thoma, Daniel; Bredell, Marius; Kruse Gujer, Astrid; Grätz, Klaus W; Weber, Franz E (2013). Bone regeneration by the osteoconductivity of porous titanium implants manufactured by selective laser melting: A histological and micro computed tomography study in the rabbit. Tissue Engineering. Part A, 19(23-24):2645-2654. 
DOI: https://doi.org/10.1089/ten.TEA.2012.0753 
Bone regeneration by the osteoconductivity of porous titanium implants manufactured by selective laser melting: A histological and $\mu \mathrm{CT}$ study in the rabbit.

Michael de Wild, $\mathrm{PhD}^{1}$

Ralf Schumacher ${ }^{1}$

Kyrill Mayer ${ }^{1}$

Erik Schkommodau, $\mathrm{PhD}^{1}$

Daniel Thoma, DDS ${ }^{2}$

Marius Bredell, MD, DDS ${ }^{3}$,

Astrid Kruse Gujer, MD,DDS ${ }^{3}$

Klaus W. Grätz, MD,DDS ${ }^{3}$

Franz E. Weber, $\mathrm{PhD}^{3,4}$

${ }^{1}$ University of Applied Sciences Northwestern Switzerland, School of Life Sciences, Institute for Medical and Analytical Technologies

${ }^{2}$ University of Zurich, Center for Dental Medicine, Clinic of Fixed and Removable Prosthodontics and Dental Material Science.

${ }^{3}$ University Hospital, Division of Cranio-Maxillofacial and Oral Surgery, Oral Biotechnology \& Bioengineering, Frauenklinikstrasse 24, 8091 Zürich.

${ }^{4}$ Zurich Center for Integrative Human Physiology (ZIHP), University of Zurich

Address for correspondence

Prof. Franz E. Weber, University Hospital, Division of Cranio-Maxillofacial and Oral Surgery, Oral Biotechnology \& Bioengineering, Frauenklinikstrasse 24, 8091 Zürich. Tel: +41 44255 5055, Fax: +41 44255 4179, E-mail: franz.weber@zzm.uzh.ch 


\section{Abstract}

The treatment of large bone defects still poses a major challenge in orthopaedic and cranio-maxillofacial surgery. One possible solution could be the development of personalized porous titanium-based implants designed to meet all mechanical needs with a minimum amount of titanium and maximum osteopromotive properties so that it could be combined with growth factor loaded hydrogels or cell constructs to realize advanced bone tissue engineering strategies. Such implants could prove useful for mandibular reconstruction, spinal fusion, the treatment of extended long bone defects, or to fill in gaps created upon autograft harvesting. The aim of this study was to determine the mechanical properties and potential of bone formation of light weight implants generated by Selective Laser Melting (SLM). We mainly focused on osteoconduction, since this is a key feature in bone healing and could serve as back-up for osteoinduction and cell transplantation strategies. To that end, defined implants were produced by SLM and their surfaces were either left untreated, sandblasted or sandblasted/acid etched. In vivo bone formation with the different implants was tested throughout calvarial defects in rabbits and compared to untreated defects. Analysis by $\mu \mathrm{CT}$ and histomorphometry revealed that all generatively produced porous $\mathrm{Ti}$ structures were well osseointegrated into the surrounding bone. The histomorphometric analysis revealed that bone formation was significantly increased in all implant treated groups compared to untreated defects and significantly increased in sand blasted implants compared to untreated ones. Bone bridging was significantly increased in sand blasted acid etched scaffolds. Therefore scaffolds manufactured by SLM should be surface treated. Bone augmentation beyond the original bone margins was only seen in implant treated defects, indicating an osteoconductive potential of the implants that could be utilized 
clinically for bone augmentation purposes. Therefore, designed porous, lightweight structures have potential for bone regeneration and augmentation purposes, especially when complex and patient-specific geometries are essential.

\section{Introduction}

Surgeons are in an on-going search for the ideal solution for bridging larger bony defects in the facial and non-facial skeleton. Titanium foams tested in vitro with human osteoblasts have shown osteoblast colonization and differentiation into mature bone cells, and consequently belong to suitable bone substitute materials in mechanically demanding sites (1). Porous titanium scaffolds with a homogeneous pore size distribution can be produced by means of powder metallurgy or CVD coating of vitreous carbon scaffolds $(2,3)$. Metal injection methods (4) allow forming porous foams with open porosity by means of $\mathrm{NaCl}$ as placeholders (5). The watersoluble placeholders, however, are randomly distributed. Therefore, with all these methods it is impossible to define the location and size of dedicated micrometre-size channels, gradients or patterns. Additionally, in all these architectures, the special distribution of the pores is mainly unsystematic and unplanned (6) and the exact porous structure is not reproducible.

Additive Manufacturing (AM, formerly referred to as Rapid Manufacturing) is a layer-by-layer production method that allows production of simple (7) as well as complex-shaped structures based on Computer Aided Design (CAD) data sets (8-10). Laser-based AM processes (Selective Laser Melting SLM) allow the production of bone implants made of metals such as titanium and titanium-based alloys (8, 11-15) with exactly defined strut size as small as $200 \mu \mathrm{m}(16)$.

Biomaterial-tissue interactions and bone healing (17) are dependent on the chemistry and topography of the artificial material $(14,18-22)$. A rough sandblasted 
and acid-etched surface, for example, enhances the proliferation of bone cells and stimulates the secretion of the extra cellular matrix (15). A Sandblasted and acidetched surface, one of the most effective artificial surface structures on commercially pure titanium (c.p.Ti) to be accepted by bony tissue, is based on a moderately rough SLA topography (23). This binary procedure of the so-called sandblasted and acidetched surface leads to a fast osseointegration, e.g. with dental implants $(12,24,25)$. It was shown in-vitro that SLM fabricated structures with native, sandblasted and acid-etched, sandblasted, polished or vibratory grinded surfaces show an identical cytocompatibility compared to conventional titanium surfaces (26).

The final aim of the overall project is to generate defined scaffolds by SLM for the treatment of large bone defects to be used in conjunction with growth factor loaded hydrogels or cell constructs for bone tissue engineering. In this initial study we evaluated the mechanical properties, osteoconduction and bone augmentation properties of defined titanium-based open porous scaffolds produced by SLM used as a bone substitute in calvarial defects in rabbits, and compared them to untreated defects.

\section{Materials and Methods:}

\section{Implant design and production}

The titanium structures for this study were designed with the Software Solidworks (www.solidworks.com) and Magics (www.materialise.com), as displayed in figure 1a. The implants have an open-porous lattice and a stepped cylindrical shape with an upper outer diameter of $7.5 \mathrm{~mm}$, a lower outer diameter of $6 \mathrm{~mm}$ and a height of $3.8 \mathrm{~mm}$. Rod thickness was set to $200 \mu \mathrm{m}$. The open porous channels with a quadratic cross section of $700 \mu \mathrm{m} \times 700 \mu \mathrm{m}$ are designed in an orthogonal 
arrangement with an overall porosity of $83.5 \%$. The designed surface area of the model is $411.5 \mathrm{~mm}^{2}$, whereas the enwrapping stepped cylinder has a surface of $169.0 \mathrm{~mm}^{2}$, i.e. 2.4 times smaller.

The implants were produced in the SLM Realizer 100 Selective Laser Melting machine (SLM Solutions, Lübeck, Germany) as displayed in figure $1 \mathrm{~b}$ and operated with a continuous wave Ytterbium-fibre laser with a wavelength between 1068 and $1095 \mathrm{~nm}$. The raw material was Ti-powder (Ti grade II according to ASTM F67, 20$63 \mu \mathrm{m}$ particle size, SLM Solutions, Germany) with a $\mathrm{d}_{50}$-value of $30 \mu \mathrm{m}$. The laser parameters were adjusted to an energy density $E_{v}$ of $63 \mathrm{~J} / \mathrm{mm}^{3}$. After fabrication (Fig. 1c), the samples were cleaned from adhering powder particles by compressed air and ultrasonic treatment. For reasons of handling during production and implantation, a transfer pin is connected to the implant via a predetermined breaking point (Fig. 1C).

\section{Evaluation of the mechanical properties of the implant material.}

The mechanical properties of the structures were determined in a universal material testing machine (Zwick Roell $100 \mathrm{kN}$ ) under uniaxial compressive load. The implants were placed horizontally, lying between two hard metal compression inserts simulating the biomechanical loading on the scaffolds during and after the operation. The force and deformation were recorded during the strain controlled compression phase with a constant strain of $0.001 \mathrm{~s}^{-1}$ at room temperature.

\section{Surface Modification and Analysis}

Three different types of implant surfaces were used in this study: a) native SLM, b) sandblasted and c) sandblasted and acid-etched surfaces. The latter two types were blasted with corundum particles MS-EKR80A at 5 bar for 60 seconds on a PEENMATIC 620S (IEPCO AG, Switzerland). Subsequently the samples c) were 
treated in a hot mixture of acid $\mathrm{HCl}\left(32 \%\right.$, Fluka) : $\mathrm{H}_{2} \mathrm{SO}_{4}(95 \%$, J.T. Baker) : ultrapure $\mathrm{H}_{2} \mathrm{O}$ (resistivity $18.2 \mathrm{M} \Omega \mathrm{cm}$, ELGA Purelab Option-Q DV 25) $(2: 1: 1 \mathrm{v} / \mathrm{v})$ at $93^{\circ} \mathrm{C}$ for 15 minutes and then rinsed three times with ultrapure water (resistivity 18.2 $\mathrm{M} \Omega \mathrm{cm})$ in an ultrasonic bath.

Two-dimensional and three-dimensional surface roughness were analysed according to EN ISO $4287: 1998$ and ISO 13565-2:1996-12 standards. Three roughness values were experimentally determined by Confocal Laser Scanning Microscope (Olympus Lext OLS 3100) with a 50x objective. An area of $100 \mu \mathrm{m} \times 100$ $\mu \mathrm{m}$ was analysed at the intersection points of the lattice. The evaluation of the height descriptive roughness parameters $\mathrm{Sra}, \mathrm{SRq}$ and $\mathrm{SRz}$ and the spatial roughness parameter RSm and Rku was done with a cut-off wavelength of $\lambda=1 / 10=10 \mu \mathrm{m}$.

The surface morphology and chemistry were analysed by Scanning Electron Microscopy (SEM, Hitachi TM-1000, 15 kV, Solid State Backscattered Electron Detector) equipped with an energy dispersive X-ray spectrometer (EDX, SwiftED-TM detector, Na11 - U92).

\section{Sample preparation}

All samples were ultrasonically cleaned in a $4 \%$ Deconex $^{\circledR}$ 15PF (Beiersdorf Münchenstein, Switzerland) solution at $90^{\circ} \mathrm{C}$ for 5 minutes, then cleaned three times in ultrapure water (resistivity $18.2 \mathrm{M} \Omega \mathrm{cm}$ ) for 15 minutes in an ultrasonic bath and two times passivated in concentrated nitric acid $\left(65 \% \mathrm{HNO}_{3}\right.$, Fluka) under ultrasonic agitation. Before packaging, the samples were cleaned and sterilized in high purity oxygen RF plasma (PDC-32G, Harrick, Ithaca, NY, USA, oxygen purity $99.9995 \%$, Carbagas) at $29.7 \mathrm{~W}$ for 5 minutes. The SLA samples were packed under inert argon atmosphere in a sealed vial filled with sterile $0.9 \% \mathrm{NaCl}$ solution. Samples with the native SLM surface and sandblasted SLM surface were packed in empty vials. All 
vials then were sealed in sterilization bags. Prior to the in-vivo tests, the samples underwent gamma-sterilization with 25 kGy.

\section{Surgical procedure}

Five adult (12 months old) New Zealand White rabbits, weighing between 3 and $4 \mathrm{~kg}$, were used in the present study. The animals were kept in a purposedesigned room for experimental animals and were fed a standard laboratory diet. The study was evaluated and accepted by the responsible Veterinary Authority of the Kanton Zurich. Animals were anesthetized by injection of $65 \mathrm{mg} / \mathrm{kg}$ ketamine and $4 \mathrm{mg} / \mathrm{kg}$ xylazine and maintenance was with isofluoran $/ \mathrm{O}_{2}$. The surgical area was disinfected and a straight incision was made from the nasal bone to the midsagital crest. The soft tissues were reflected and the periosteum was elevated from the site. In the area of the right and left parietal and frontal bones, four evenly distributed 6 $\mathrm{mm}$ diameter craniotomy defects were prepared with a trephine bur under copious irrigation with sterile saline. Care was exercised to avoid injury of the dura. The surgical area was flushed with saline to remove bone debris. Each of the animals received all 4 different treatment modalities: empty, a) native SLM implant, b) sandblasted SLM implant, and c) sandblasted and acid-etched SLM implant (Fig. 1d). The treatment modalities were assigned at random for the first animal and thereafter cyclic permuted clockwise for the next three animals. For the fifth animal, treatment modalities were again assigned at random. After carefully placing the implants into the defects, the soft tissues were closed with interrupted sutures. After a healing period of 8 weeks, the rabbits were sacrificed by an overdose of ketamine. The skull containing all four craniotomy sites was removed and placed in $40 \%$ ethanol. 


\section{Embedding}

The specimens were prepared with a sequential water substitution process that involved $48 \mathrm{~h}$ in $40 \%$ ethanol, $72 \mathrm{~h}$ in $70 \%$ ethanol (changed every $24 \mathrm{~h}$ ), $72 \mathrm{~h}$ in $96 \%$ ethanol and finally $72 \mathrm{~h}$ in $100 \%$ ethanol. The samples were then placed in xylene for $72 \mathrm{~h}$ (changed every $24 \mathrm{~h}$ ). Next, the samples where infiltrated by placing them in methyl methacrylate (MMA) for $72 \mathrm{~h}$ (Fluka 64200) followed by three days in $100 \mathrm{ml} \mathrm{MMA}+2 \mathrm{~g}$ di-benzoylperoxid (Fluka 38581) at 4 Co. Samples were embedded by placing them in $100 \mathrm{ml} \mathrm{MMA}+3 \mathrm{~g}$ di-benzoylperoxid $+10 \mathrm{ml}$ plastoid $\mathrm{N}$ or dibutyl phthalate (Merck 80019.25 ) and allowing polymerization to occur at 37 Co in an incubator. After embedding, the skull was cut in four pieces each containing one craniotomy site by using an Exakt 300P saw (Exakt, Norderstedt, Germany).

\section{$\mu C T$ analysis}

Hard tissue and implant material distribution in the embedded, separated craniotomy sites were determined by a SkyScan $1172^{\mathrm{TM}}$ high-resolution micro CT scanner (SkyScan NV, Kontich, Belgium), equipped with a 100 kV / $100 \mu \mathrm{A}$ X-ray source and a 10 megapixel X-ray sensitive CCD camera. The flat samples were rotated around the vertical symmetry axis in steps of $0.4^{\circ}$ with the circular closing rings in horizontal orientation, see figure $1 \mathrm{a}$. The specimens were individually $360^{\circ}$-scanned using an accelerating voltage of $100 \mathrm{kV}$ and a beam current of $100 \mu \mathrm{A}$, resulting in 900 projection images. A $0.5 \mathrm{~mm}$ Al filter was used to increase the mean photon energy. The reconstruction was carried out by the cluster-based NRecon software (Version 1.4.4, SkyScan NV, Kontich, Belgium), which distributed the calculation parallel to 5 computers. The reconstruction leads to a set of 937 stacked slices with a dynamic range of 8 bit. The morphological analysis was done with the CTAn software (version 1.8.0.5, SkyScan NV, Kontich, Belgium). 


\section{Histology}

After $\mu \mathrm{CT}$ analysis, embedded craniotomy sites were sectioned by a diamond band saw (Exakt 300P) in the middle of the defect, glued to a support and sectioned again, so that a $200 \mu \mathrm{m}$ thick sample from the middle was attached to the support. The thickness of this sample was further reduced to $40-60 \mu \mathrm{m}$ by a grinding machine (Exakt $420 \mathrm{CS}$ ). To visualize tissues, the samples were surface stained by toluidine blue. Digital images were taken and processed with an image analysis program (Adobes Photoshop CS3). Quantitative evaluation of bone regeneration was done by applying standard morphometrical techniques as reported earlier $(27,28)$.

\section{Bone bridging}

Bone bridging was determined in the middle section. First, the areas with bone tissue were projected onto the x-axis. Next, the stretches of the $x$-axis where bone formation had occurred at any level were summed up as described earlier $(28,29)$. Bone bridging is given in percentage of the defect width $(6 \mathrm{~mm})$ where bone formation has occurred.

\section{Statistical analysis}

The primary analysis unit was the animal. For all parameters tested, the four treatment modalities were compared with a Friedman test, followed by pairwise comparison of treatment modalities with the Wilcoxon signed rank test for dependent data (IBM SPSS v.19). P-values for the probability of significant differences between treatments are displayed in the graphs and significance was set at $\mathrm{P}<0.05$. Data from 5 rabbits are presented. Values are reported as mean \pm SD and displayed as box-plots ranging from the $25^{\text {th }}$ (lower quartile) to the 75 th (upper quartile) percentile including the median and whiskers showing the minimum and maximum values. 


\section{Results}

Process and implant characterization

In order to qualify the production process, the produced SLM pieces were compared with the structure virtually defined in CAD. The geometric differences detected between the CAD model and materialized physical implants are mainly in the strut size: The planned CAD strut size of $200 \mu \mathrm{m}$ were found to be $238 \pm 29 \mu \mathrm{m}$ for the as-produced implants with native surface. The pore sizes of the native implants have a size of $578 \pm 27 \mu \mathrm{m}$. The strut size of the sandblasted implants is $212 \pm 27 \mu \mathrm{m}$, with pore sizes of $642 \pm 37 \mu \mathrm{m}$. Surface treatment by sandblasting and acid etching changes the elemental composition from $99.75 \% \mathrm{Ti}$ to $90.5 \% \mathrm{Ti}$ and 9.5\% Al due to corundum particles that stick to the surface and are not removed by ultrasonic cleaning. After the acid-etching, most of the $\mathrm{Al}_{2} \mathrm{O}_{3}$ particles are detached and the amount of $\mathrm{Al}$ on the surface composition is reduced to $1 \%$. These surface treatments also reduce the surface roughness $\mathrm{SR}_{a}$ of the native SLM implant from $3.33 \pm 0.27 \mu \mathrm{m}$ to $0.94 \pm 0.07 \mu \mathrm{m}$ for sandblasted surface and to $1.16 \pm 0.11 \mu \mathrm{m}$ for the sandblasted and acid-etched surface (Table 1). The Confocal Laser Scanning Microscopic analysis assessed that the amplitude roughness parameters and spatial roughness parameters were reduced upon surface modification. Furthermore, the effective surface area of the native topography is reduced by the treatments: whereas the native surface shows a surface area ratio Sdr of 2.64 (i.e. ratio between the effective surface and the projected area), the sandblasted surface is reduced to Sdr $=1.44$ and the sandblasted and acid-etched surface to $S d r=1.76$.

The change in the surface topography is also evident in representative SEM pictures taken from the different implant types (Fig. 2). The native SLM surface (left) is covered by spherical particles from the starting powder material that are not fully melted but only sintered to the implant. The sandblasted surface (center) exhibits a 
flaked topography arising from the abrasive blasting process. The sandblasted and acid-etched surface (right) is characterized by a superposition of cavities with a diameter of roughly $50 \mu \mathrm{m}$ from the sandblasting with pits of diameter $1-2 \mu \mathrm{m}$ from the acid etching process.

Static compression tests of the implants $(n=5)$ resulted in a compressive strength of $R_{m}=15.9 \pm 0.4 \mathrm{MPa}$ and a compressive yield strength of $\mathrm{R}_{0.2}=12.1 \pm 0.4 \mathrm{MPa}$. The Young's Modulus of the lattice material was determined to be $763 \pm 176 \mathrm{MPa}$. For comparison, bulk SLM titanium was mechanically characterized in tensile tests: $R_{m}=662.1 \pm 20.6 \mathrm{MPa}, R_{0.2}=555.2 \pm 19.4 \mathrm{MPa}$, $\mathrm{E}_{0}=119 \pm 13.7 \mathrm{GPa}$ (Table 2).

\section{Bone formation}

After the operation, no adverse reaction was observed and the animals remained in good health. For each implant, the volume of the entire implant and the volume of the bone grown into the implant and their ratio (bone volume/total volume, BV/TV) were determined based on $\mu \mathrm{CT}$ data reconstructed to a 3D model (Fig. 3). The mean value of the volume of bone related to the entire volume of the implant determined by $\mu \mathrm{CT}$ accounted for $10.46 \pm 1.95 \%$ for the empty control, $19.23 \pm 6.39 \%$ for the native SLM implant, $25.23 \pm 7.82 \%$ for sandblasted SLM implants and $14.81 \pm 1.74 \%$ for sandblasted and acid-etched SLM implants. These $\mu \mathrm{CT}$ results were not significantly different between the empty control and the 3 different surface modifications of SLMimplants. The lattice structures used here proved not to be suitable for tomographic investigations as they exhibit a large surface/solid ratio with huge interface scattering. Therefore, the distribution of newly formed bone was studied based on the ground sections. 
In the ground sections, no signs of inflammation could be detected. Bone formation occurred close to and in contact with the bone substitutes (Fig. 4, 5), which indicates a good biocompatibility over the first 8 weeks upon implantation for all SLM implants irrespective of the surface treatment. The histomorphometric analysis of the middle section given in mean number of bone points was $44.40 \pm 14.88$ points in the empty control samples, $128 \pm 49.09$ points for SLM implants, $174.20 \pm 63.92$ points for sandblasted SLM, and $175.20 \pm 75.97$ points for sandblasted and acid-etched SLM implants. The number of bone points falling on mineralized bone in the defect in all groups with implants was significantly higher $(P=0.043)$ than in the control group where no implant was placed. Between the groups with implants, the number of bone points was not significantly different, irrespective of the surface treatment.

By dividing the middle section in an area of presumably resected bone and an area outside of the original bone margins, it appeared that bone formation beyond the original bone margins was facilitated by the presence of this implant type (Fig. 6a). Bone formation in the control group without implant was almost exclusively restricted to the original bone area (Fig. 6b). In all groups with implants, significantly ( $P=0.043)$ more bone formed compared to the control group in both the area outside the original bone margins and the area of the resected bone, irrespective of the surface treatment (Fig. 6). In the presumably original bone margins, significantly $(P=0.043)$ more bone formed in sandblasted than in untreated SLM implants.

Another way to look at the distribution of newly formed bone is to assess the percentage of defect bridging. Based on the histology of the middle sections, the untreated defects exhibit defect bridging of $56.67 \pm 23.13 \%$, SLM of $78.33 \pm 26.09 \%$, sandblasted SLM of $86.67 \pm 13.94 \%$, and sandblasted and acid-etched SLM of $96.67 \pm 7.46 \%$, respectively. Compared to untreated defects, the increase in defect 
bridging by bone is significant for the sandblasted and acid-etched implants only $(P=0.043)($ Fig. 6)

\section{Discussion}

In this study, open porous titanium structures were prepared by Additive Manufacturing and placed in the calvaria of New Zealand rabbits. The lattice was defined with orthogonal struts of $200 \mu \mathrm{m}$ thickness and a pore size of $700 \mu \mathrm{m}$ width. The thickness of the native implants produced by SLM, however, are thicker due to spherical powder particles that are sintered onto the solid surface (Fig. 2). The emerging cavities, therefore, are smaller than designed. By sandblasting, the decorating particles are removed (see figure 2), the wall thickness is reduced and the cavities become larger. It is important to note that the final implant geometry is dependent on the CAD model geometry, the SLM processing parameter as well as the successive surface treatment. The laser parameters can be adjusted in order to compensate for these facts. It is known that the pore dimensions used here $(578 \mu \mathrm{m}$, resp. $642 \mu \mathrm{m}$ ) allow good osseointegration and vascularization in metallic (30) and ceramic foams $(31,32)$.

The scaffolds were mechanically characterized in an axial biomechanical loading case simulating pressure on the scaffold in the calvaria (Table 2). The static compression tests showed that the mechanical strength of this scaffold is in the upper range of cancellous bone, Therefore this scaffold could substitute for the use of cancellous autologous bone (33).

All implants showed good in-vivo performance with mineralized bone and no indication of adverse tissue reactions (Fig. 4, 5). For all three types of implants, the amount of bone within the implant and around the implant was significantly higher than in the control group where no implant was placed (Fig. 6). Therefore, the 
titanium-based scaffolds stimulated additional bone formation and served as guidance cues even beyond the original bone margins. When the same model was used for calcium phosphate-based materials like synthetic hydroxyapatite/silica oxide-based granules (27), a cotton-wool-like nanocomposite (34), synthetic calcium phosphate granules (35) or deproteinized bovine mineral matrix granules $(27,28,34)$, overall bone formation was either not increased or the increase was not significant.

Defect bridging, another clinically relevant parameter, also failed to be increased for all aforementioned calcium phosphate-based materials when compared to untreated empty defects. The newly developed titanium-based scaffolds evaluated here, however, increased defect bridging significantly, at least when the surface was sandblasted and acid etched. The superior performance in the stimulation of additional bone formation and defect bridging of our titanium-based scaffolds compared to deproteinized bovine bone matrix, the gold standard bone substitute in dentistry and newly developed bone substitutes tested in the same setting $(27,34,35)$ might arise from the minimal amount of material we used due to our scaffold design, the gapless interconnectivity throughout the whole scaffold and/or the well-known excellent performance of titanium in a bone regeneration context.

A systemic review on surface roughness of titanium revealed that moderately rough surfaces with a roughness between 1.00-2.00 $\mu \mathrm{m}$ are superior to both smoother $(0.50-1.00 \mu \mathrm{m})$ or rougher $(>2.00 \mu \mathrm{m})$ surfaces $(36,37)$. Therefore, native SLM fabricated materials have to undergo a surface treatment like sandblasting for an optimal performance in a bony environment. This was in line with our results, since significantly more mineralized tissue was formed in the original defect margins in sandblasted scaffolds with a roughness determined as arithmetic mean deviation of the surface (SRa) of $0.94 \pm 0.07$ compared to native SLM scaffolds with a SRa value of $3.33 \pm 0.27$ (Tab. 1, Fig. 6b). 
It was already shown in-vivo that solid Ti6Al4V implants can be generatively manufactured by e-beam melting and that they are well-integrated into rabbit femur and tibia after 6 weeks (38). SLM was also used to produce experimental titaniumbased rods with 4 non-connected channels of different dimensions to study the relation between osteoconduction and channel dimension (7). From the tested channels with a width between 500 and $1200 \mu \mathrm{m}$, osteoconduction in terms of bone formation in the more central part was best for the $500 \mu \mathrm{m}$ channels. The pore size of interconnecting pores in our 3D scaffolds was between 578 and $642 \mu \mathrm{m}$ and therefore close to the optimal values.

Also by SLM, a 3D-titanium-based scaffold was fabricated to resemble human cancellous bone (39). In this case, the titanium struts were $400-800 \mu \mathrm{m}$ thick and therefore much thicker than our regular shaped scaffold with strut size of $220 \mu \mathrm{m}$ and the porosity varied from $55-75 \%$. For our scaffolds with a porosity of $83 \%$, as evident in figure $4 \mathrm{c}$, up to $50 \%$ of the area of the middle section where the scaffold resided was filled with mineralized tissue. In terms of bone ingrowth, Pattanayak and coworkers found bone formation predominantly at the outer surface and only a very small fraction estimated to be below $5 \%$ inside the scaffold. This is evident from the histological illustrations (39). Specific data on bone ingrowth and osteoconductivity was, however, not provided by these authors. In contrast, the present study demonstrates that our newly designed scaffolds aiming at a minimal amount of titanium by high porosity, minimal strut thickness, maximal interconnectivity of the pore forming channels in the $550-650 \mu \mathrm{m}$ range and an optimized surface treatment are truly osteoconductive, surpass even calcium phosphate-based bone substitutes in this respect and guide new bone formation throughout the entire scaffold.

The design of our scaffolds realized by SLM followed by a surface treatment allow a tight connection to the body and a reduced stress shielding due to its 
decreased stiffness, which matches the overall mechanical properties of cancellous bone. Therefore it could serve as mechanically stable, osteoconductive scaffold to contain mechanically less stable osteoinductive materials like hydrogels and/or cell constructs for bone tissue engineering purposes. For bone regeneration, as tested here, the osteoconductivity of our scaffolds is potent enough to guide new bone to be formed at sites outside the original bone margins, so that our scaffolds could prove useful not only as a bone substitute suitable for the treatment of substantial bone defects but also for challenging bone augmentation purposes in oral surgery and dentistry.

In conclusion, we designed and produced a titanium based bone substitute by SLM to resemble mechanically and structurally cancellous bone as well as to avoid stress shielding. This in combination with a high porosity of $83 \%$ and a pore size of 500-600 $\mu \mathrm{m}$ led to a highly osteoconductive bone substitute. The in vivo results using SLM native, SLM sandblasted and SLM sandblasted, acid etched compared to an empty defect revealed that overall bone formation increased significantly. Our results also showed that bone formed in the scaffold outside the original bone margins, and that sandblasted, acid etched scaffolds showed a significant increase in defect bridging. In addition we noticed that especially the treated SLM surface scaffolds show a superior osteoconductivity which facilitates more bone formation, and could be further developed for bone substitutes suitable for the reconstruction of large bony defects.

\section{Acknowledgements :}


The authors would like to thank Alexandr Tchouboukov for technical assistance and the partial financial support by AOCMF, the Cranio-Maxillofacial Specialty of the AO Foundation via the project (10-C-37W).

\section{Disclosure Statement}

No competing financial interests exist.

\section{References}

1. St-Pierre JP, Gauthier M, Lefebvre LP, Tabrizian M. Three-dimensional growth of differentiating MC3T3-E1 pre-osteoblasts on porous titanium scaffolds. Biomaterials.26:7319-28. 2005.

2. Imwinkelried T. Mechanical properties of open-pore titanium foam. J Biomed Mater Res A.81:964-70. 2007.

3. Levine BR, Sporer S, Poggie RA, Della Valle CJ, Jacobs JJ. Experimental and clinical performance of porous tantalum in orthopedic surgery. Biomaterials.27:467181. 2006.

4. Singh R, Lee PD, Lindley TC, Kohlhauser C, Hellmich C, Bram M, et al. Characterization of the deformation behavior of intermediate porosity interconnected Ti foams using micro-computed tomography and direct finite element modeling. Acta Biomaterialia.6:2342-51. 2010.

5. Bansiddhi A, Sargeant TD, Stupp SI, Dunand DC. Porous NiTi for bone implants: a review. Acta Biomater.4:773-82. 2008.

6. Körner C, Singer RF. Processing of Metal Foams - Challenges and Opportunities. Advanced Engineering Materials.2:159-65. 2000.

7. Fukuda A, Takemoto M, Saito T, Fujibayashi S, Neo M, Pattanayak DK, et al. Osteoinduction of porous $\mathrm{Ti}$ implants with a channel structure fabricated by selective laser melting. Acta Biomater.7:2327-36. 2011.

8. Mullen L, Stamp RC, Fox P, Jones E, Ngo C, Sutcliffe CJ. Selective laser melting: a unit cell approach for the manufacture of porous, titanium, bone in-growth constructs, suitable for orthopedic applications. II. Randomized structures. J Biomed Mater Res B Appl Biomater.92:178-88. 2010.

9. Murr LE, Quinones SA, Gaytan SM, Lopez MI, Rodela A, Martinez EY, et al. Microstructure and mechanical behavior of Ti-6Al-4V produced by rapid-layer manufacturing, for biomedical applications. J Mech Behav Biomed Mater.2:20-32. 2009.

10. Warnke PH, Douglas T, Wollny P, Sherry E, Steiner M, Galonska S, et al. Rapid prototyping: porous titanium alloy scaffolds produced by selective laser melting for bone tissue engineering. Tissue Eng Part C Methods.15:115-24. 2009.

11. Haberland C. Fundamental studies on the influence of process parameters on the properties of SLM parts. 2nd User Meeting. Paderborn2007. 
12. Weber FE, Eyrich G, Gratz KW, Maly FE, Sailer HF. Slow and continuous application of human recombinant bone morphogenetic protein via biodegradable poly(lactide-co-glycolide) foamspheres. Int J Oral Maxillofac Surg.31:60-5. 2002.

13. Li JP, de Wijn JR, van Blitterswijk CA, de Groot K. Porous Ti6Al4V scaffolds directly fabricated by 3D fibre deposition technique: effect of nozzle diameter. J Mater Sci Mater Med.16:1159-63. 2005.

14. Zhao G, Zinger O, Schwartz Z, Wieland M, Landolt D, Boyan BD. Osteoblastlike cells are sensitive to submicron-scale surface structure. Clin Oral Implants Res.17:258-64. 2006.

15. Zhao G, Raines AL, Wieland M, Schwartz Z, Boyan BD. Requirement for both micron- and submicron scale structure for synergistic responses of osteoblasts to substrate surface energy and topography. Biomaterials.28:2821-9. 2007.

16. Schumacher R, de Wild M, Fabbri S, Yildiz A, Schkommodau E. Rapid Manufactoring of Individual Ti-6AI-4V Bone Implants. Eur Cell Mater.17:22. 2009.

17. Marx RE. Bone and bone graft healing. Oral Maxillofac Surg Clin North Am.19:455-66, v. 2007.

18. Brunette DM, Tengvall $P$, Textor M. Titanium in Medicine: Material Science, Surface Science, Engineering, Biological Response and Medical Applications. Berlin: Springer; 2001.

19. Ferguson SJ, Broggini N, Wieland M, de Wild M, Rupp F, Geis-Gerstorfer J, et al. Biomechanical evaluation of the interfacial strength of a chemically modified sandblasted and acid-etched titanium surface. J Biomed Mater Res A.78:291-7. 2006. 20. Kasemo B, Gold J. Implant surfaces and interface processes. Adv Dent Res.13:8-20. 1999.

21. Rupp F, Scheideler L, Olshanska N, de Wild M, Wieland M, Geis-Gerstorfer J. Enhancing surface free energy and hydrophilicity through chemical modification of microstructured titanium implant surfaces. J Biomed Mater Res A.76:323-34. 2006.

22. Schuler M, Kunzler TP, de Wild M, Sprecher CM, Trentin D, Brunette DM, et al. Fabrication of TiO2-coated epoxy replicas with identical dual-type surface topographies used in cell culture assays. J Biomed Mater Res A.88:12-22. 2009.

23. Kieswetter K, Schwartz Z, Hummert TW, Cochran DL, Simpson J, Dean DD, et al. Surface roughness modulates the local production of growth factors and cytokines by osteoblast-like MG-63 cells. J Biomed Mater Res.32:55-63. 1996.

24. Bornstein MM, Lussi A, Schmid B, Belser UC, Buser D. Early loading of nonsubmerged titanium implants with a sandblasted and acid-etched (SLA) surface: 3-year results of a prospective study in partially edentulous patients. Int $\mathrm{J}$ Oral Maxillofac Implants. 18:659-66. 2003.

25. Buser D, Broggini N, Wieland M, Schenk RK, Denzer AJ, Cochran DL, et al. Enhanced bone apposition to a chemically modified SLA titanium surface. J Dent Res.83:529-33. 2004.

26. de Wild M, Maier K, Schneider M, Tschumi S, Schumacher R, H. A. Surface Modification and In-vitro Investigation of Generatively Produced Implants. BIOmaterialien.11:157. 2010.

27. Kruse A, Jung RE, Nicholls F, Zwahlen RA, Hammerle CH, Weber FE. Bone regeneration in the presence of a synthetic hydroxyapatite/silica oxide-based and a xenogenic hydroxyapatite-based bone substitute material. Clin Oral Implants Res.22:506-11. 2011.

28. Schmidlin PR, Tchouboukov A, Wegehaupt FJ, Weber FE. Effect of cerium chloride application on fibroblast and osteoblast proliferation and differentiation. Arch Oral Biol.57:892-7. 2012. 
29. Kruse A, Jung RE, Nichols F, Zwahlen RA, Hämmerle CHF, Grätz KW, et al. Bone regeneration in the presence of a synthetic hydroxyapatite oxide based and a xenogenic hydroxyapatite based bone substitute material. EAO Warschau. 2008.

30. Bobyn JD, Stackpool GJ, Hacking SA, Tanzer M, Krygier JJ. Characteristics of bone ingrowth and interface mechanics of a new porous tantalum biomaterial. J Bone Joint Surg Br.81B:907-14. 1999.

31. Jensen SS, Yeo A, Dard M, Hunziker E, Schenk R, Buser D. Evaluation of a novel biphasic calcium phosphate in standardized bone defects: a histologic and histomorphometric study in the mandibles of minipigs. Clin Oral Implants Res.18:75260. 2007.

32. Malmstrom J, Adolfsson E, Arvidsson A, Thomsen P. Bone response inside free-form fabricated macroporous hydroxyapatite scaffolds with and without an open microporosity. Clin Implant Dent Relat Res.9:79-88. 2007.

33. Wintermantel E, Ha S-W. Medizintechnik - Life Science Engineering. Berlin, Heidelberg: Springer-Verlag 2009.

34. Schneider OD, Weber F, Brunner TJ, Loher S, Ehrbar M, Schmidlin PR, et al. In vivo and in vitro evaluation of flexible, cottonwool-like nanocomposites as bone substitute material for complex defects. Acta Biomater.5:1775-84. 2009.

35. Schmidlin PR, Nicholls F, Kruse A, Zwahlen RA, Weber FE. Evaluation of moldable, in situ hardening calcium phosphate bone graft substitutes. Clin Oral Implants Res. 2011.

36. Wennerberg A, Albrektsson T. Effects of titanium surface topography on bone integration: a systematic review. Clin Oral Implants Res.20 Suppl 4:172-84. 2009.

37. Wennerberg A, Albrektsson T. On implant surfaces: a review of current knowledge and opinions. Int J Oral Maxillofac Implants.25:63-74. 2010.

38. Thomsen P, Malmstrom J, Emanuelsson L, Rene M, Snis A. Electron beammelted, free-form-fabricated titanium alloy implants: Material surface characterization and early bone response in rabbits. J Biomed Mater Res B Appl Biomater.90:35-44. 2009.

39. Pattanayak DK, Fukuda A, Matsushita T, Takemoto M, Fujibayashi S, Sasaki $\mathrm{K}$, et al. Bioactive Ti metal analogous to human cancellous bone: Fabrication by selective laser melting and chemical treatments. Acta Biomater.7:1398-406. 2011.

\section{Figures}

Figure 1: Selective Laser Melting Process and implant design. a) Implant design including lattice dimension. b) Schema of the selective laser melting process. Metal powder is locally melted by an intensive infrared laser beam $(100 \mathrm{cW}$ TEM00) that traces the layer geometry (down to $30 \mu \mathrm{m}$ layer thickness), http://www.sIm-solutions.com/. c) Photograph of implants on the building platform supported on a transfer pin after excavation from the powder. d) Intraoperative situation: three implants and an empty craniotomy defect.

Figure 2: Surface characterization of the implants. SEM images of native SLM (left row), sandblasted SLM (middle row), and sandblasted and acid-etched 


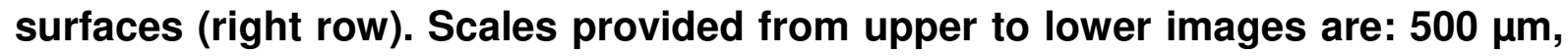
$100 \mu \mathrm{m}$, and $30 \mu \mathrm{m}$.

Figure 3: $\mu \mathrm{CT}$ reconstruction. (a) $\mu \mathrm{CT}$ image (left) and the reconstructed bone (right) of an empty and (b) a defect treated with a SLM sandblasted implant are shown as representative examples. The white regions (right) show the identified bone area within the ROI after density segmentation. (c) 3D visualization of a transversal section with a thickness of $60 \mu \mathrm{m}$ of the 3D data set from the same implant as in fig. 3(b) with sandblasted surface: the bone appears red and the titanium implant blue. Scale bars indicate 1 millimetre.

Figure 4: Histological sections from the middle of the defect from one exemplary animal 8 weeks postoperatively. (a) Untreated defect (empty), (b) native SLM (c) sandblasted SLM and (d) sandblasted and acid-etched surface. Scale bars indicate 1 millimetre. Original magnifications were 100-fold. Bone appears as greyish purple. The size of the original defect is indicated in a.

Figure 5: High magnifications of histological sections from the middle of the defect 8 weeks postoperatively. (a,d) native SLM $(b, e)$ sandblasted SLM and $(c, f)$ sandblasted and acid-etched surface. The white square indicates the location of the related higher magnification picture in the lower panel. Black scale bars (upper panel) indicate $500 \mu \mathrm{m}$; white scale bars (lower panel) $100 \mu \mathrm{m}$. Original magnifications were 200 (a-c)-and 1000 (d-f)-fold. Titanium (black) is indicated by $\mathrm{Ti}$. The greyish-stained bone tissue is lamellar bone (also new, but later formed) on the initial woven bone structures stained purple.

Figure 6: Bone formation in and outside the original bone margins. (a) Bone formation beyond the original bone is significantly increased in all implant groups compared to the control group. An illustration of the region of bone formation beyond the original margins (blue area) is provided in the upper panel. b) Bone formation in the original margins of the bone. Bone formation in the middle section is significantly increased with SLM implants, irrespective of their surface treatment compared to the control groups without implant. The area of the original bone margins (red) is illustrated in the upper panel. In the margins of the original bone, significantly more bone formed in the sandblasted SLM group compared to the native SLM group. Mineralization is given as number of grid points fallen on mineralized tissue in the defined area of interest (blue or red).

Figure 7: Defect bridging is the percentage of the defect where new bone formation has occurred. 
Roughness amplitude parameters:

SRa: arithmetic mean deviation of the surface.

SRq: root-mean-square deviation of the surface.

SRz: peak to valley height.

Roughness spacing parameter:

RSm: mean line peak spacing.

Roughness amplitude distribution parameters:

Rku: surface kurtosis.

Table 2: Mechanical characterization of SLM bar and scaffold 
Table 1. Surface Roughness parameters depending on the chemical and mechanical surface modifications. Values are averages over $n=6$ for each surface.

\begin{tabular}{|l|l|l|l|}
\hline Roughness parameter & SLM native & sandblasted & SLA \\
\hline SRa $[\mu \mathrm{m}]$ & $3.33 \pm 0.27$ & $0.94 \pm 0.07$ & $1.16 \pm 0.11$ \\
\hline SRq $[\mu \mathrm{m}]$ & $4.41 \pm 0.34$ & $1.22 \pm 0.08$ & $1.53 \pm 0.22$ \\
\hline SRz $[\mu \mathrm{m}]$ & $46.87 \pm 4.22$ & $11.88 \pm 1.20$ & $16.00 \pm 3.78$ \\
\hline RSm $[\mu \mathrm{m}]$ & $12.79 \pm 3.80$ & $10.16 \pm 1.93$ & $7.70 \pm 0.84$ \\
\hline Rku $[\mu \mathrm{m}]$ & $3.70 \pm 1.08$ & $3.43 \pm 1.17$ & $2.86 \pm 0.42$ \\
\hline
\end{tabular}

Roughness amplitude parameters:

SRa: arithmetic mean deviation of the surface.

SRq: root-mean-square deviation of the surface.

SRz: peak to valley height.

Roughness spacing parameters:

RSm: mean line peak spacing.

Roughness amplitude distribution parameters:

Rku: surface kurtosis.

Surface Roughness parameters depending on the chemical and mechanical surface modifications. Values are averages over $n=6$ for each surface. 
Table 2: Mechanical characterization of SLM bar and scaffold

\begin{tabular}{|l|l|l|l|l|l|}
\hline sample & Porosity $[\%]$ & $\mathbf{R}_{\mathbf{0 . 2}}[\mathrm{MPa}]$ & $\mathbf{E}[\mathrm{MPa}]$ & $\mathbf{R}_{\mathrm{m}}[\mathrm{MPa}]$ & Pore size $[\mathrm{mm}]$ \\
\hline SLM Ti scaffold & $\mathbf{8 3 . 5}$ & $\mathbf{1 2 . 1} \pm \mathbf{0 . 4}$ & $\mathbf{0 . 7} \pm \mathbf{0 . 2}$ & $\mathbf{1 5 . 9} \pm \mathbf{0 . 4}$ & $\mathbf{0 . 7}$ \\
\hline SLM Ti bar & $\mathbf{0}$ & $\mathbf{5 5 5 . 0 \pm 1 9 . 4}$ & $\mathbf{1 1 9 . 0 \pm 1 3 . 7}$ & $\mathbf{6 6 2 . 9} \pm \mathbf{2 0 . 6}$ & $\mathbf{0 . 0}$ \\
\hline
\end{tabular}

Mechanical characterization of SLM bar and scaffold 

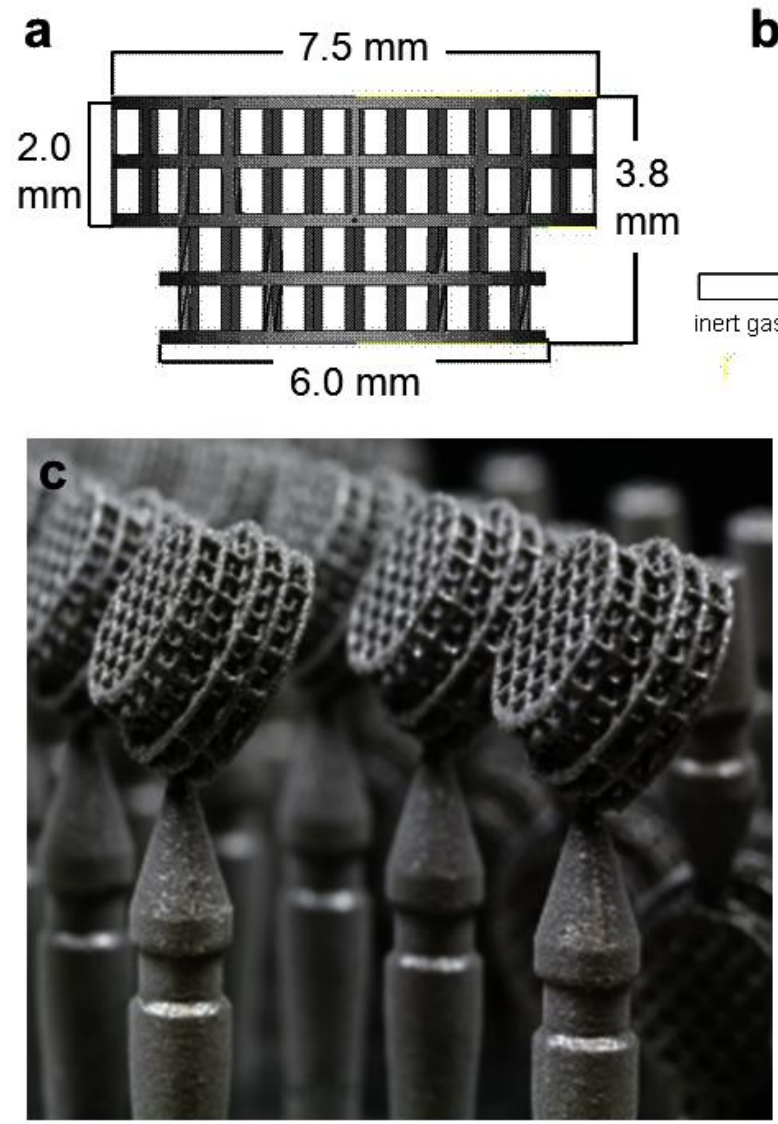
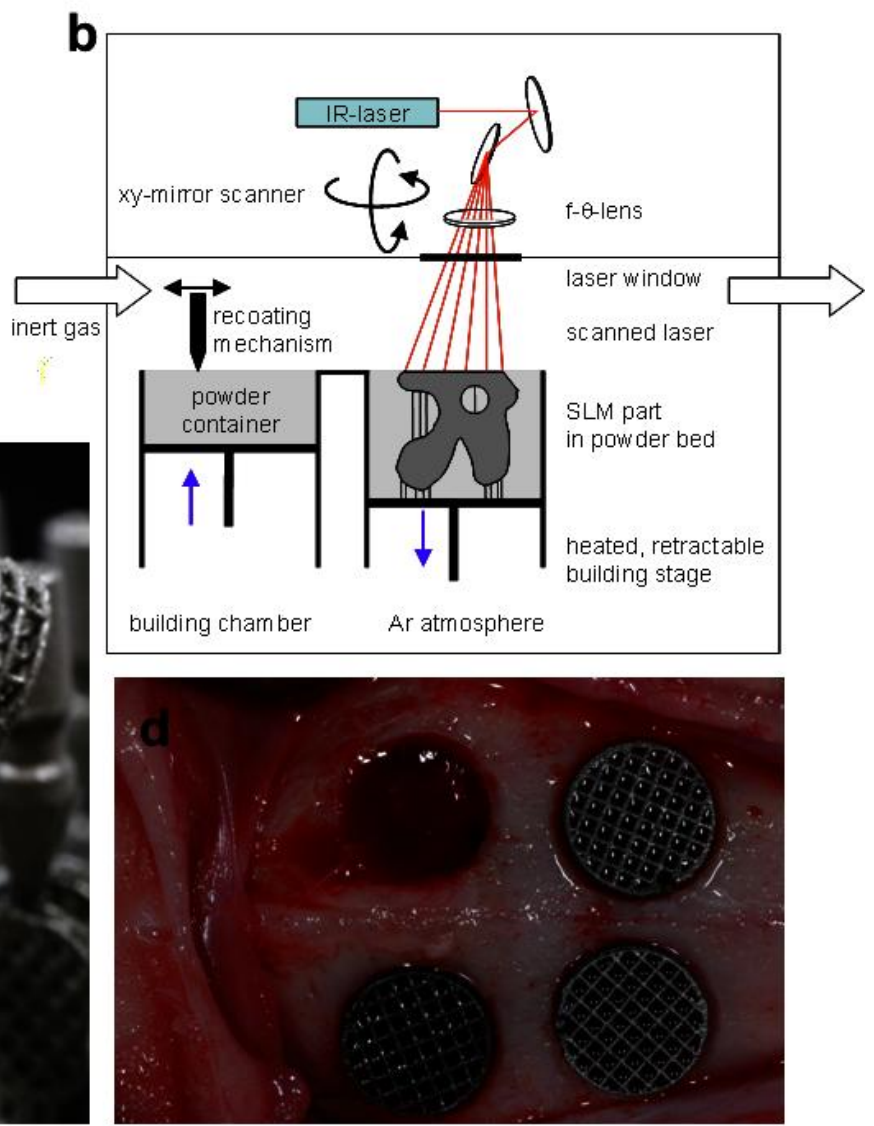

Selective Laser Melting Process and implant design. a) Implant design including lattice dimension. b) Schema of the selective laser melting process. Metal powder is locally melted by an intensive infrared laser beam (100cW TEM00) that traces the layer geometry (down to $30 \mu \mathrm{m}$ layer thickness), http://www.slm-solutions.com/.c) Photograph of implants on the building platform supported on a transfer pin after excavation from the powder. d) Intraoperative situation: three implants and an empty craniotomy defect. 
Page 25 of 31

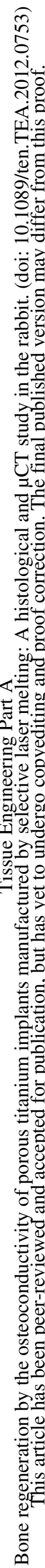
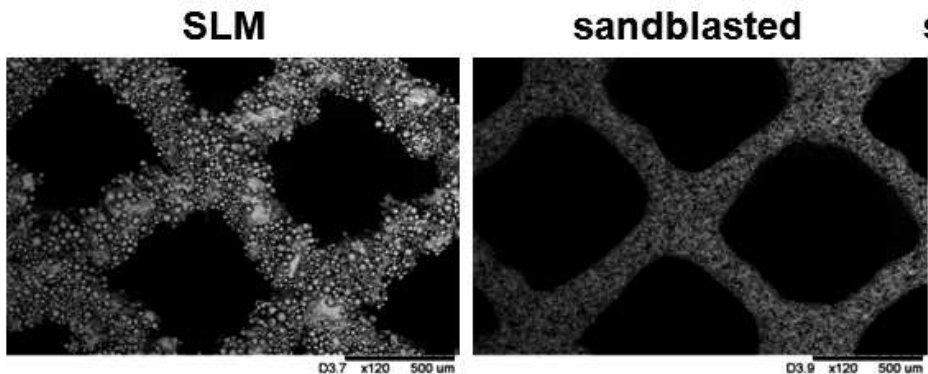

sand blasted/acid etched
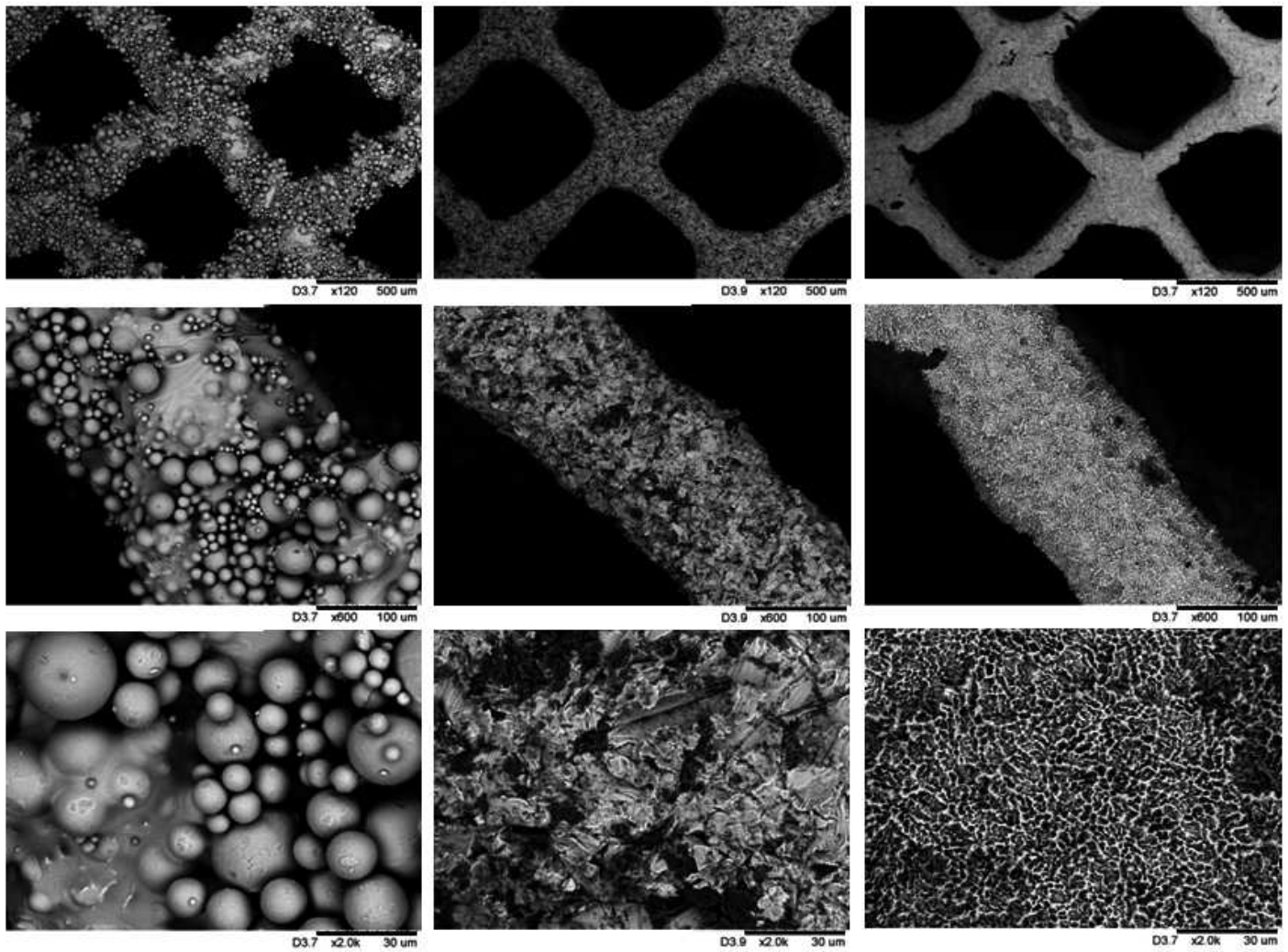

Surface characterization of the implants. SEM images of native SLM (left row), sandblasted SLM (middle row), and sandblasted/acid etched SLM surfaces (right row). Scales provided from upper to lower images are: $500 \mu \mathrm{m}, 100 \mu \mathrm{m}$, and $30 \mu \mathrm{m}$. 


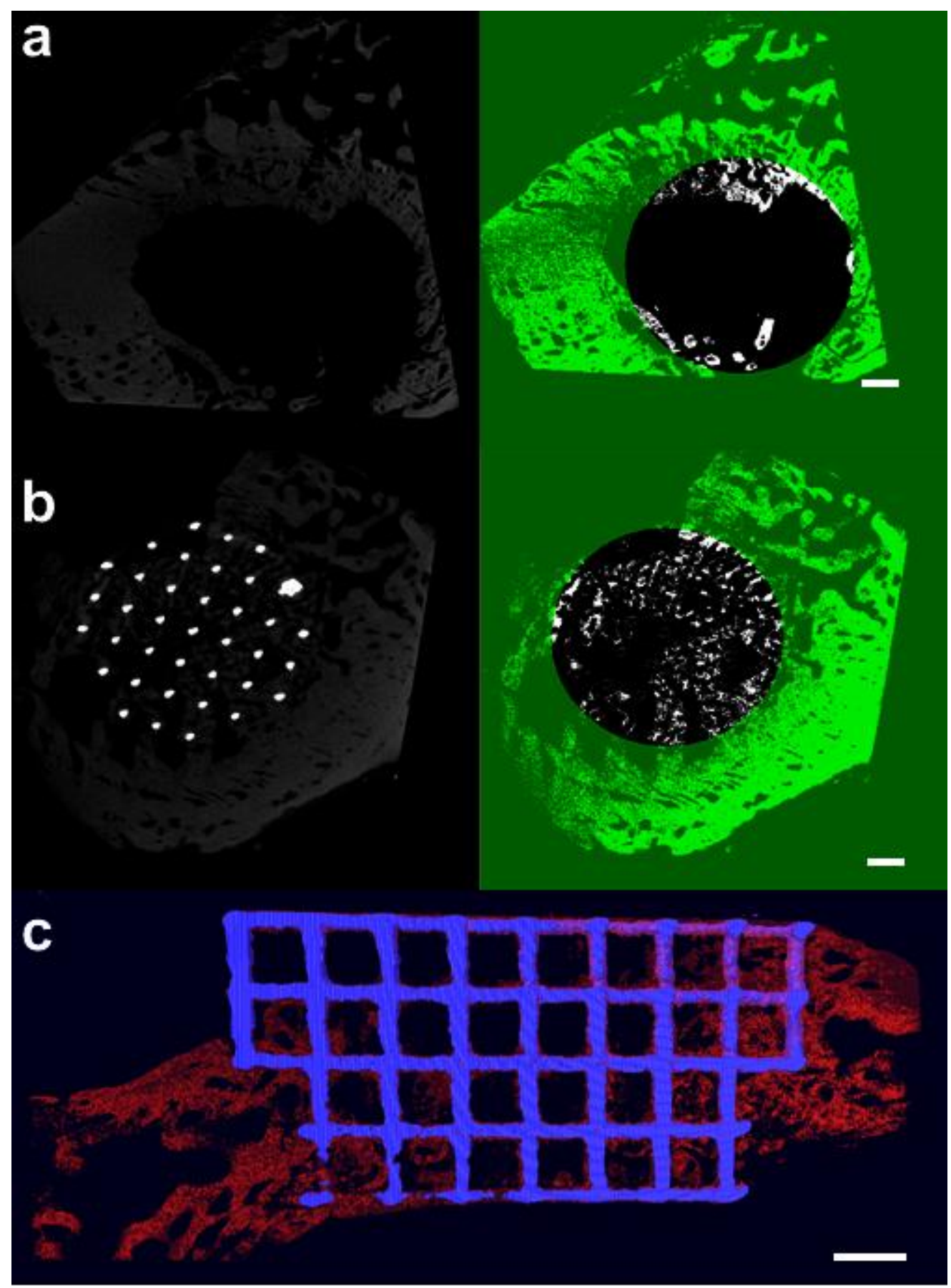

$\mu \mathrm{CT}$ reconstruction. (a) $\mu \mathrm{CT}$ image (left) and the reconstructed bone (right) of an empty and (b) a defect treated with a SLM sandblasted implant are shown as representative examples. The white regions (right) show the identified bone area within the $\mathrm{ROI}$ after density segmentation. (c) 3D visualization of a transversal section with a thickness of $60 \mu \mathrm{m}$ of the 3D data set from the same implant as in fig. 3(b) with sandblasted surface: the bone appears red and the titanium implant blue. Scale bars indicate 1 millimetre. 
Page 27 of 31

กิ

‥

กิ윰

떱.

ฮี

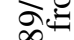

$\stackrel{0}{0 .}$

0

휼

.

큔

巳ठ

$\Xi \because \bar{\Xi}$

긍르

क⿺⿻一⿰冫⿰亅⿱丿丶丶]

记

클

స్․ㅇำ

80

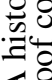

4

$<$ 当

E.

000

웡

0.

50屯

으을

웡요

吾

莺

్ㅡㄹ

苛.

:

竞

를

告

을

to

ते

.

을

8

o

D

초ำ

둥

․․․

․․․․

๑ั 


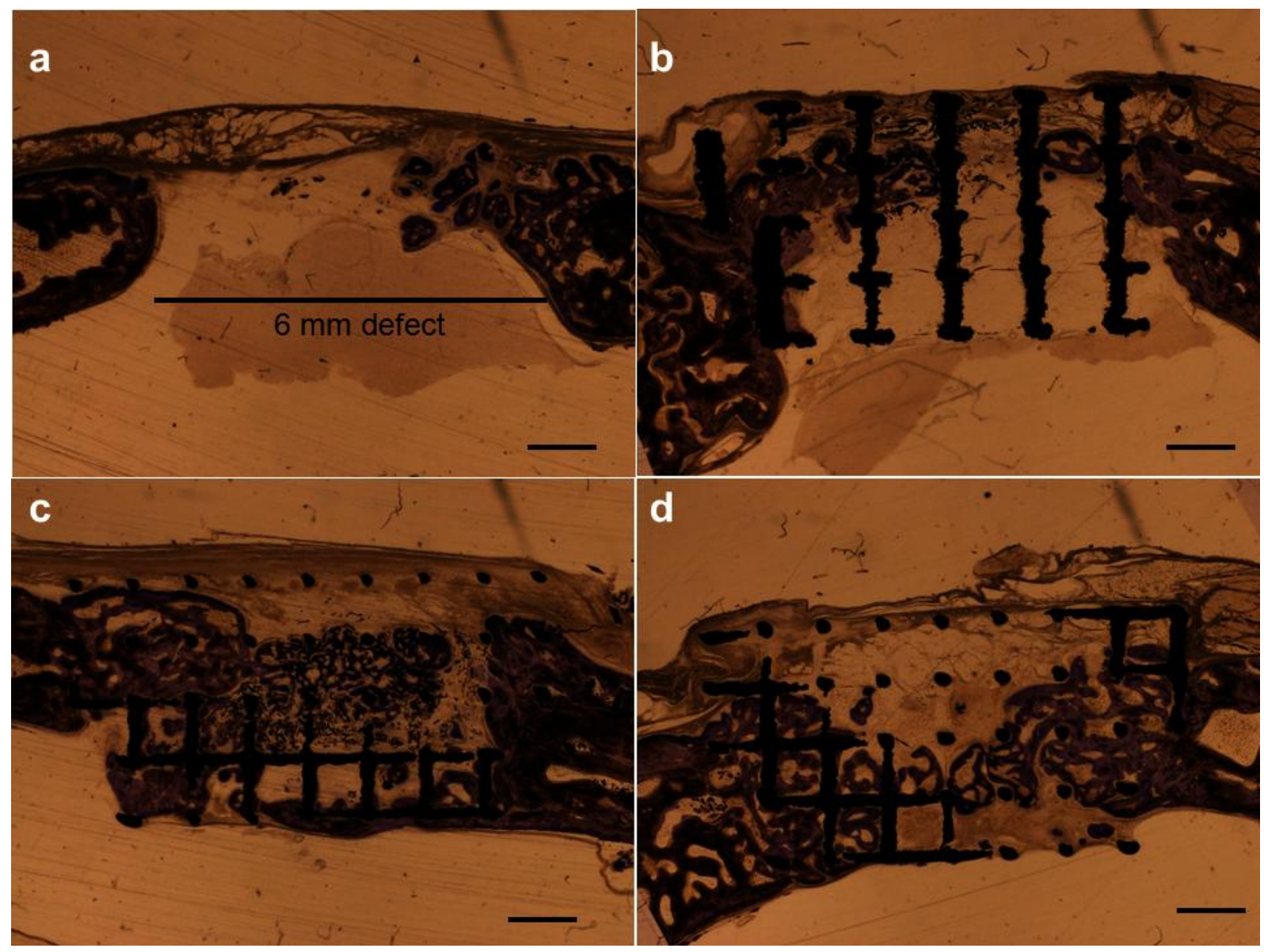

Histological sections from the middle of the defect from one exemplary animal 8 weeks postoperatively. (a) Untreated defect (empty), (b) native SLM (c) sandblasted SLM and (d) sandblasted/acid etched SLM surface. Scale bars indicate 1 millimetre. Original magnifications were 100 -fold. Bone appears as greyish purple. The size of the original defect is indicated in a. 


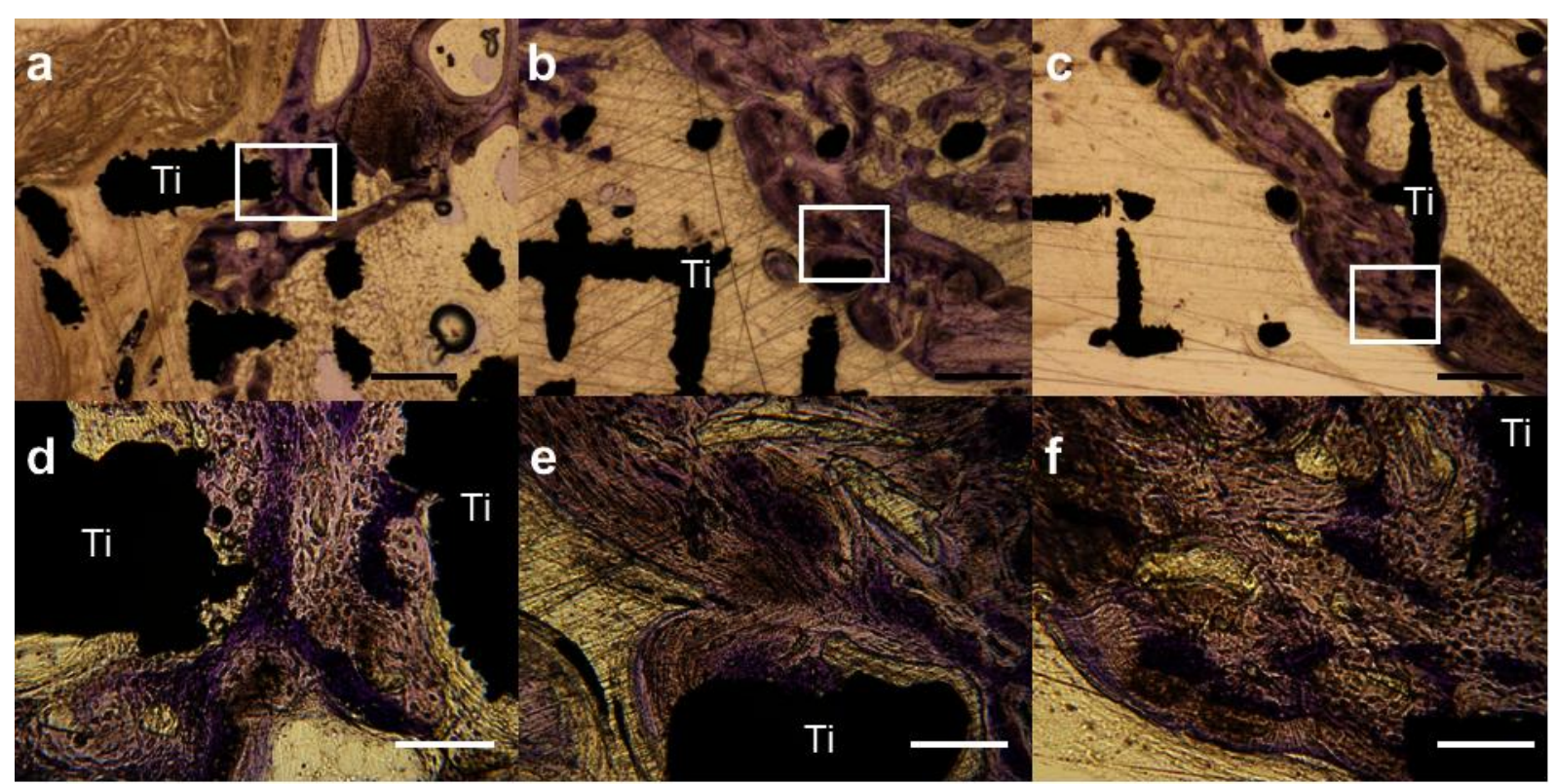

High magnifications of histological sections from the middle of the defect 8 weeks postoperatively. (a,d) native SLM (b,e) sandblasted SLM and (c,f) sandblasted/acid etched SLM surface. The white square indicates the location of the related higher magnification picture in the lower panel. Black scale bars (upper panel) indicate 500 $\mu \mathrm{m}$; white scale bars (lower panel) $100 \mu \mathrm{m}$. Original magnifications were 200 (a-c)and 1000 (d-f)-fold. Titanium (black) is indicated by Ti. The greyish-stained bone tissue is lamellar bone (also new, but later formed) on the initial woven bone structures stained purple. 
a
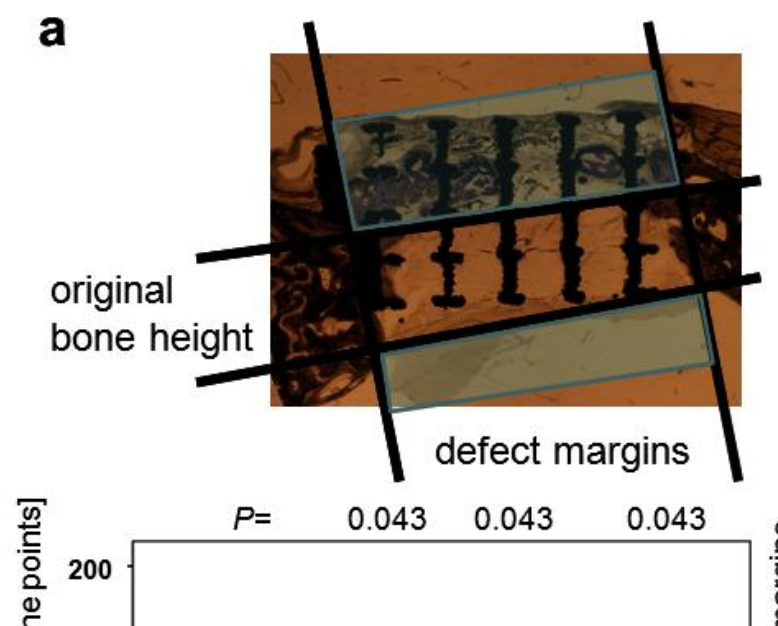

$\stackrel{0}{\circ}$

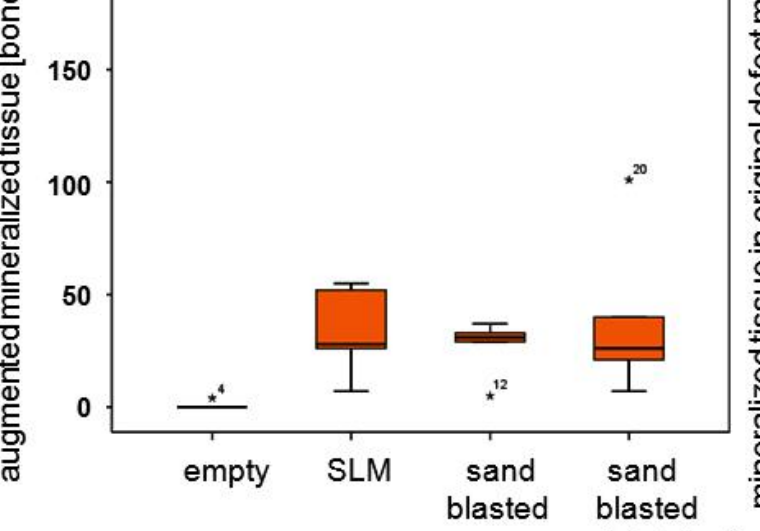

acid etched b
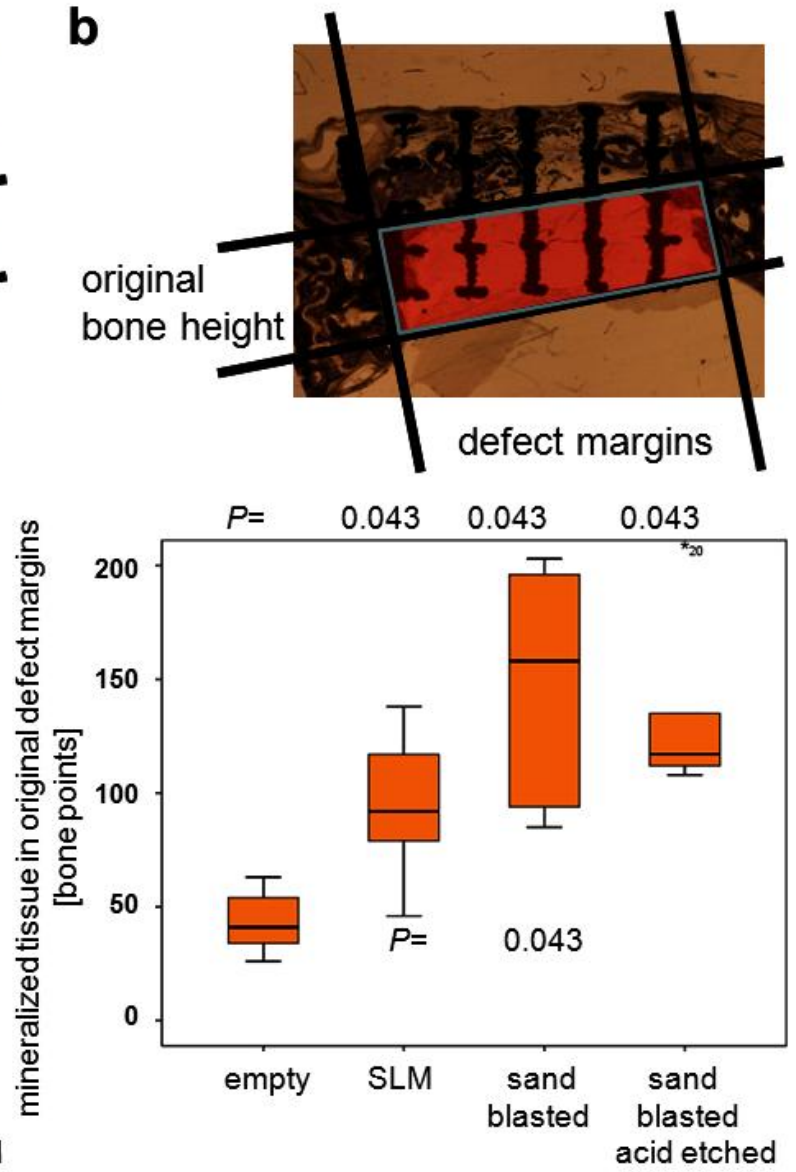

Bone formation in and outside the original bone margins. (a) Bone formation beyond the original bone is significantly increased in all implant groups compared to the control group. An illustration of the region of bone formation beyond the original margins (blue area) is provided in the upper panel. b) Bone formation in the original margins of the bone. Bone formation in the middle section is significantly increased with SLM implants, irrespective of their surface treatment compared to the control groups without implant. The area of the original bone margins (red) is illustrated in the upper panel. In the margins of the original bone, significantly more bone formed in the sandblasted SLM group compared to the native SLM group. Mineralization is given as number of grid points fallen on mineralized tissue in the defined area of interest (blue or red). 


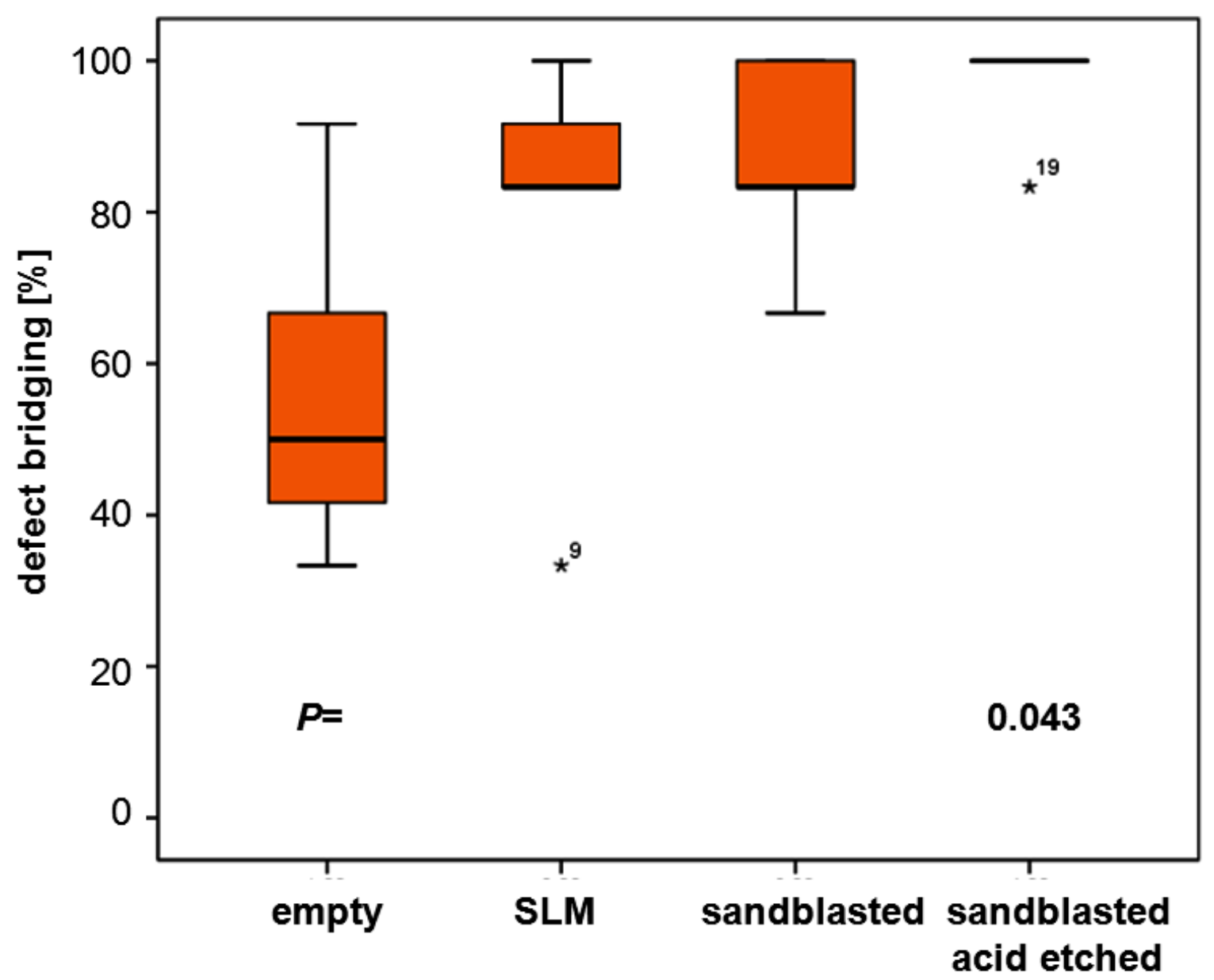

Defect bridging is the percentage of the defect where new bone formation has occurred. 